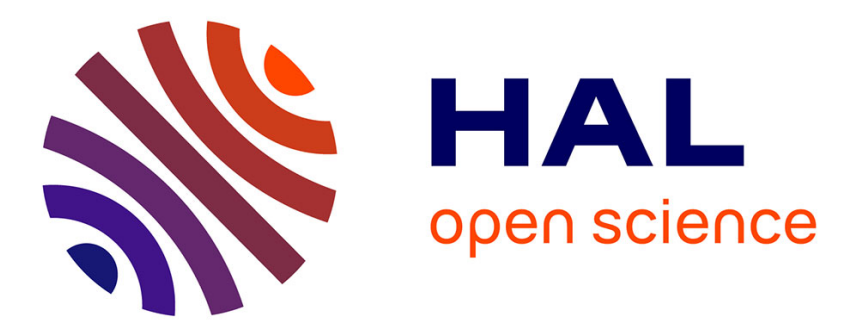

\title{
ACTIVE AND PASSIVE STUDIES OF AMORPHOUS CHALCOGENIDE IR EMITTERS
}

\author{
P. Walsh, Amine Jaafar, M. Thompson, D. Adler
}

\section{To cite this version:}

P. Walsh, Amine Jaafar, M. Thompson, D. Adler. ACTIVE AND PASSIVE STUDIES OF AMORPHOUS CHALCOGENIDE IR EMITTERS. Journal de Physique Colloques, 1981, 42 (C4), pp.C4317-C4-322. 10.1051/jphyscol:1981467 . jpa-00220924

\section{HAL Id: jpa-00220924 https://hal.science/jpa-00220924}

Submitted on 1 Jan 1981

HAL is a multi-disciplinary open access archive for the deposit and dissemination of scientific research documents, whether they are published or not. The documents may come from teaching and research institutions in France or abroad, or from public or private research centers.
L'archive ouverte pluridisciplinaire HAL, est destinée au dépôt et à la diffusion de documents scientifiques de niveau recherche, publiés ou non, émanant des établissements d'enseignement et de recherche français ou étrangers, des laboratoires publics ou privés. 


\title{
ACTIVE AND PASSIVE STUDIES OF AMORPHOUS CHALCOGENIDE IR EMITTERS
}

\author{
P.J. Wa1sh, A. Jaafar, M.J. Thompson ${ }^{*}$ and D. Adler** \\ Fairleigh Dickinson University, Teaneck, NJ 07666, U.S.A. \\ * The University of Sheffield, Sheffieza S1 3JD, United Kingdom \\ ** Massachusetts Institute of Technology, Cambridge, Mass., 02139, U.S.A.
}

\begin{abstract}
Optical properties of thin-film light-emitting amorphous diodes of $\overline{\mathrm{Si}}_{18} \mathrm{Te}_{45^{\mathrm{As}}}{ }_{28} \mathrm{Ge}_{9}$ have been measured both at the University of Sheffield and at MIT. We determined the wavelength dependence of the refractive index of the deposited glass, the passive external interference mode structure of the fabricated devices with reflecting lower contacts and semi transparent upper contacts and the corrected infrared emission spectrum on the same devices. At currents just above the optical threshold in the on-state the emission is narrow band, at a wavelength consistent with earlier experiments, while at higher currents the emission shows the narrow component with a broad component which follows the shape of the passive external transmittance. The optical threshold current of these types of devices increases with increased thickness of the transparent upper contact indicating the optical feedback requirement of this emission. The various results we have obtained reinforce the presumption that the emission is stimulated.
\end{abstract}

Introduction. - Infrared emission ${ }^{1-3}$ has been observed in the on-state of amorphous chalcogenide thin film devices deposited between planar conducting electrodes of $\mathrm{Te}_{39} \mathrm{As}_{36} \mathrm{Si}_{17} \mathrm{Ge}_{7} \mathrm{P}$ and $\mathrm{As}_{50} \mathrm{Te}_{50}$. The emission has been observed only in the on-state of the amorphous films and only above a well-defined optical threshold current in the on-state which depends upon the optical reflection properties of the electrical contacts. The emission is temperature independent, relatively narrow, is situated at an energy of about half the band gap, requires a minimum thickness of amorphous film and apparently originated within the conducting pancake filament of the onstate. The emission can not be due to normal spontaneous emission and may well be stimulated emission. Table I summarizes these properties in more detail.

TABLE 1. SUMMARY OF OPTICAL PROPERTIES

\begin{tabular}{|c|c|}
\hline EFFECT & BEHAVIOR \\
\hline Temperature dependence & Substantially independent of temperature, $160^{\circ} \mathrm{K}-300^{\circ} \mathrm{K}$. \\
\hline Area dependence & $\begin{array}{l}\text { Area independent if cross-section of device is larger } \\
\text { than filament. Narrow, less than } 10 \% \text {. Measurement } \\
\text { apparatus limited. }\end{array}$ \\
\hline Current dependence & $\begin{array}{l}\text { Exists only above threshold current and in conducting } \\
\text { state. }\end{array}$ \\
\hline Threshold current & $\begin{array}{l}\text { Decreases with increasing film thickness. Increases } \\
\text { with increasing thickness of thin transmitting contact. } \\
\text { Substantially linear with excess power above threshold. } \\
\text { Half band gap. Shifts with current. }\end{array}$ \\
\hline Angular width & Large angle if externally observed. \\
\hline Contact dependence & $\begin{array}{l}\text { Requires reflecting contact. Threshold current depends } \\
\text { on reflecting contact thickness. }\end{array}$ \\
\hline Thickness dependence & Exists only above threshold thickness. \\
\hline
\end{tabular}


These devices are commonly prepared by photolithographic techniques on silicon chips and thus constitute silicon-compatible integrable light sources ${ }^{4}$. Including the experiments discussed here more than 1500 devices have shown this novel emission.

Experiments. - This work continues our investigation of the on-state emission in the material Si $18{ }^{\mathrm{Te}}{ }_{45^{A s}}{ }_{28} \mathrm{Ge}_{29}$ which we will refer to as STAG. This material is quite similar to that of Ref. 1 and has a conductivity activation energy of 0.54 ev. The devices were prepared photolithographically on a Corning 7059 glass substrate at the University of Sheffield. Fig. 1 illustrates the geometry of the devices. The active chalcogenide sits within the pores and forms a planar geometry between a thick Mo-Al lower contact and a partially transmitting Mo upper contact through which the emission is observed.

Fig. 1 One array of emitting devices. Pores are etched from the

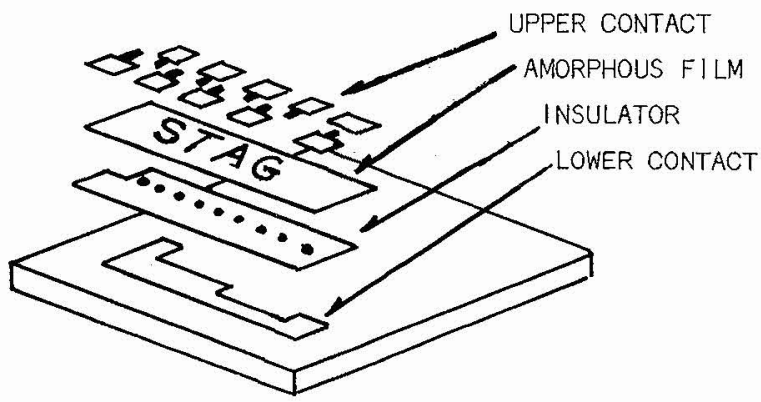
insulator and parallel upper and lower contacts bracket the STAG.

The optical emission in STAG has properties similar to that found earlier. The emission has a current threshold in the on-state. We have found that this current threshold increases with increasing thickness of the partially transparent Molybdenum upper contact. Fig.2 shows this dependence with the sputtering time of the upper Mo film used as an indicator of film thickness. The fabricated STAG devices show radiation outputs 1 to 2 orders of magnitude higher than found in Aste devices deposited under similar conditions.

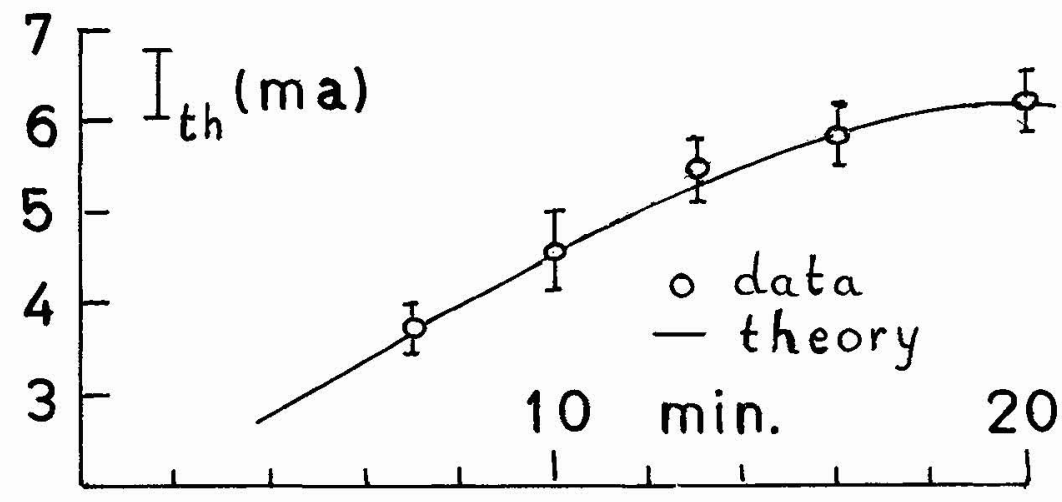

Fig. 2. Optical threshold current versus Mo deposition time for a $1.05 \mu m$ thick amorphous film at $298^{\circ} \mathrm{K}$. See text for theory. 
If the fabricated devices are viewed in $I R$ Iight incident from the device side of the silicon chip a substantial portion of the light transmits through the areas of the amorphous glass from which deposited contact strips are absent. Most of the light incident on the top thin Mo contacts will reflect because of the optical mismatch with air while all the light which strikes a lower thick contact strip will reflect. However, the remaining light will transmit through the glass in a manner determined by the interference mode structure of the thin amorphous glass on silicon. Fig. 3 shows the passive external transmittance mode structure of the amorphous film.

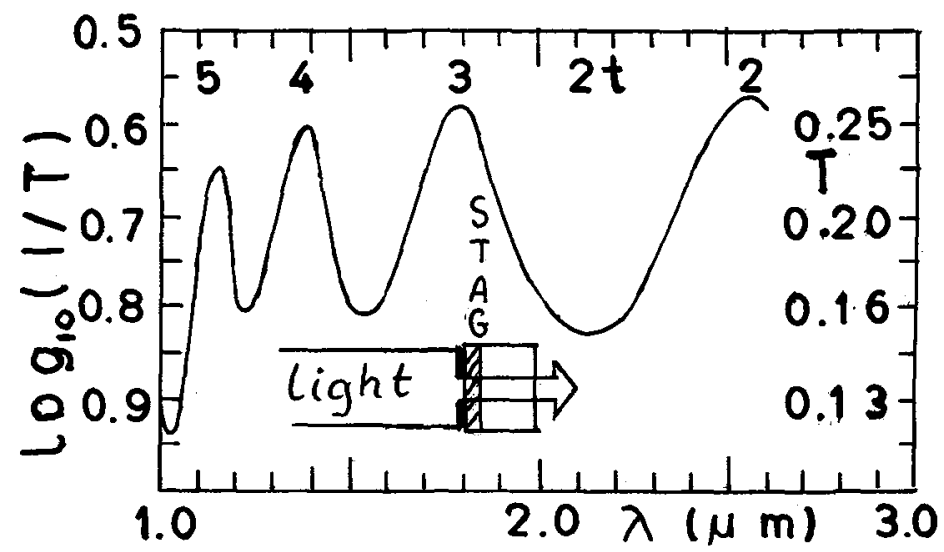

Fig. 3. Passive external transmittance of STAG film on device substrate for a $0.94 \mu \mathrm{m}$ thick film.

The peaks in the relative loss correspond to high reflectivity from the amorphous thin $\mathrm{film}$ situated on the glass substrate in air. The transmission peaks thus occur when twice the film thickness is an integral number of wavelengths of the light in the material while the transmission minima occur when twice the thickness is an odd number of half wavelengths. The film thickness was measured using a Zeiss interferometer and index of refraction was determined for the STAG material. Fig. 4 gives the index of the deposited film versus wavelength. These indices can be checked by calculating the maxima and minima of t for Fig. 3 . The indices of Fig. 4

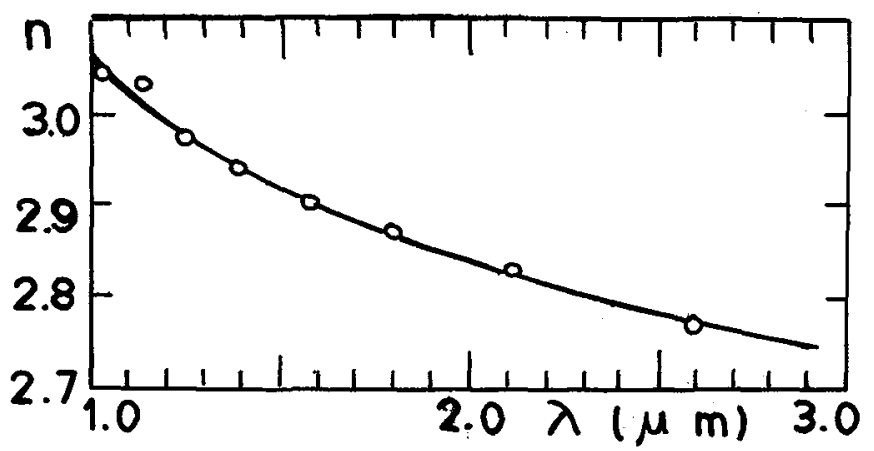

Fig. 4. Refractive index of STAG film as deposited on the device structure. 
replicate the maximum and minimum transmission within $\pm 4 \%$ is a substrate index of 1.50 is used and the exposed $\mathrm{film}$ area is taken as $21 \%$. Th is agreement requires that the film absorption in the region from 1.2 to $2.5 \mu m$ be less than several percent.

The spectral emission of STAG devices were measured using a Jerrel-Ash monochrometer at the University of Sheffield and also at MiT using an OCLi half circular variable filter. Both measurements normally used a PbS defector. The measurements at MIT were on the same set of devices whose film transmission characteristics were given in Fig. 3. The uncorrected relative outputs of the two sets of measurements are given in Fig. 5 a.

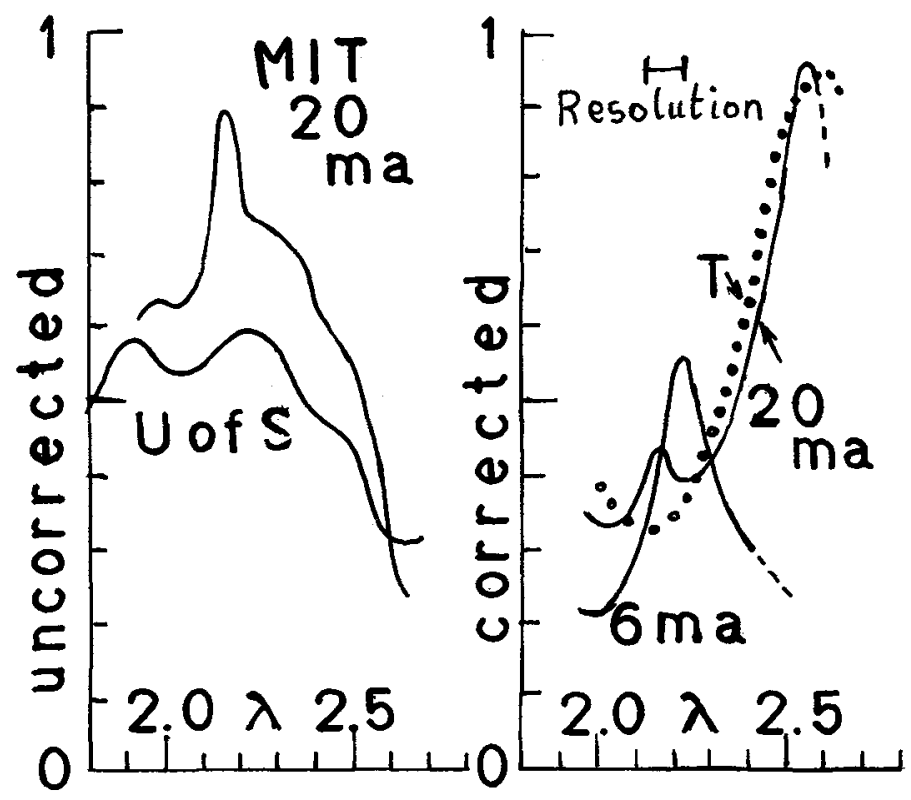

Fig. 5(a). Uncorrected output of devices at high currents. Two devices were measured at MIT each across the entire spectrum. A large number of devices were measured at the $U$ of $S$, each device across a portion of the spectrum. Typical rms variance is $\pm 15 \%$.

(b). Output measured at MIT at a high current and at a low current just above the optical threshold.

These measurements are obtained using single shot pulses whose pulse lengths are typically $1 \mathrm{~ms}$ length. The MlT data is an average of two devices using $20 \mathrm{ma}$ pulses while the $U$ of $S$ data is an average curve using many devices at high current over portions of the spectrum. The two scale magnitudes are not directly comparable. Both sets of data show a similar broad structure while the MIT data show a narrow additional component which subsequent experiments showed becomes submerged in the broader emission at high currents. Differences in the shape of the two broad curves are probably due to the response characteristics of the two different measuring systems. The apparent fall off in output at long wavelength is due in part to the decreasing response of the detectors in this region. 
At currents just above the optical threshold of a device the emission characteristics are different than at high currents. Fig. 5b shows corrected output at $6 \mathrm{ma}$ of a device with a $4 \mathrm{ma}$ optical threshold and compares the output with corrected outputs of the two $20 \mathrm{ma}$ devices of Fig. 5a. The response of the Variable Filter-PbS detection system was calibrated against an incandescent filament for these measurements. The passive transmission curve of the amorphous $f i l m$ is also shown. Note that the high current output follows the passive transmission curve while the low current output has a peak which falls part way between the external transmission peak and the external transmission minimum.

The maximum output at low current is near $2.25 \mathrm{~km}$ with a one sided half width of $0.10 \mu \mathrm{m}$ which is essentially the resolution limit of the system. The measured line width is thus measurement limited at present. The high current. peak is near $2.55 \mu \mathrm{m}$ and is very broad. The total emission is higher at $20 \mathrm{ma}$ than at $6 \mathrm{ma}$ by about 150 times because the 6 ma current is quite close to the optical threshold (4 ma) of these devices.

Discussion. - There are two puzzling features in these experiments if the presumption is made that the emission is stimulated emission requiring optical feedback. The first is the increase in optical threshold current with increasing thickness of the upper molybdenum contact and the second is the location of the emission, for a current just above the optical threshold, at a wavelength near the minimum of the passive transmission. The increased molybdenum thickness should normally produce increased reflectivity and hence optical feedback requiring a lower optical threshold current whild the minimum transmittance region normally corresponds to destructive interference of internal modes.

The anomalous behavior of thin molybdenum transparent becomes clear when we take into account the high index found for the STAG fillm. At the emission wavelengths the index is 2.8 and the mismatch with air produces a $22 \%$ reflection in the absence of a contact layer. If reasonable optical constants are chosen for molybdenum ${ }^{5}, n=2.9$ and $k=7.4$ at $2.2 \mu$, we find that thin films of molybdenum progressively reduce the surface reflectivity of STAG by matching the large STAG index to air. At $80 \AA$ of MO on STAG in air the reflectivity is reduced to about $8 \%$.

Using the equation for laser threshold in an amorphous on-state filament between reflecting contact 3 we can relate the threshold current, I th, to the contact reflectivities $R_{1}$ and $R_{2}$ as follows:

$$
I_{\text {th }}=1_{0} /\left[1-A \ln \left(1 / R_{1} R_{2}\right)\right]
$$

Here $A=1 / \alpha t_{\text {min }}$, where $\alpha$ is the laser gain in the on-state filament and $t_{\text {min }}$ is the minimum threshold thickness for optical emission, $I_{0}$ is the threshold current when $R_{1} R_{2}=1$. We fit the data of Fig. 2 by using $I_{0}=1.35 \mathrm{ma}, A^{-1}=3.25, R_{1}=0.95$ for the thick lower Al-Mo sontact, calculating $R_{2}$ from standard formulas ${ }^{5}$, and assuming a sputtering rate of $4 \AA / \mathrm{min}$. 
The location of the low current emission peak near the minimum transmission region can now be explained. Within the current filament reflection off the thick lower Al-Mo contact should produce a phase difference near $180^{\circ}$. However, the thin Mo contact produces only a slight phase change upon reflection. The 6 ma device has $1_{t h}$ near $4 \mathrm{ma}$ suggesting from $\mathrm{Fig} \cdot 2$ and a $4 \AA \mathrm{A} / \mathrm{min}$ rate that the molybdenum thickness is $40 \AA$. Computation gives a phase change of only $79^{\circ}$ upon reflection. The double film thickness, 2t, must thus produce a phase difference of $101^{\circ}$ (or $0.28 \lambda$ ) plus any multiple of $360^{\circ}$ to allow for a low loss standing optical mode between the parallel contacts. We then expect coherent modes at wavelengths near $2 t /(p+0.28) \lambda$. For $p=2, \lambda$ is at $2.31 \mu \mathrm{m}$ slightly on the long wave side of the transmission minimum. This calculation is of course suggestive only, but the general argument does require the emission at currents near optical threshold to fall near the transmission minimum. The results analyzed here are thus quite consistent with stimulated emission as the source of the emission investigated. The shift in emission toward a higher $\lambda$ at higher currents suggest that the emission process during the stimulated emission peaks near 2.5 to $2.6 \mu \mathrm{m}$.

Thanks are due to Dr. K. Homma, J. Pooladej and R. Frye for their great help in this work.

\section{REFERENCES}

1 P. J. Walsh, S. I shioka, and D. Adler, Appl. Phys. Let†. 33 (1978) 593. Thls work gives references to earlier non-planar emission studies.

2 P. J. Walsh, J. Pooladej, M. J. Thompson, and J. Allison, Appl. Phys. Let†. 34 (1979) 733 .

3 M. J. Thompson, D. Pooladej, and P. J. Walsh, J. Non-Cryst. Solids $\underline{35}$ and 36 (1980) 1111 .

4 P. J. Walsh, M. J. Thompson, and D. Pooladej, IEEE Transaction Electron Devices 28 (1981) 343 .

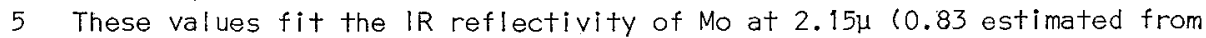
AIP Handbook, 2nd ed., Table 6g-3 (AIP, NY, 1979)) and the value $2 n k=20$, given by A. Lenham, J. Opt. Soc. Amer. 57, 473 (1967). 